\title{
Triagem da atividade antibacteriana in vitro do látex e extratos de Croton urucurana Baillon
}

\author{
Iris S. Oliveira, Joaquim C. S. Lima, Regilane M. Silva, Domingos T. O. Martins* \\ Departamento de Ciências Básicas da Saúde, Universidade Federal de Mato Grosso, 78060-900 Cuiabá-MT, \\ Brasil
}

\begin{abstract}
RESUMO: Avaliou-se a atividade antibacteriana dos látex e extratos de diferentes polaridades e farmacógenos de Croton urucurana em ensaios antimicrobianos. Os farmacógenos foram coletados em Barão de Melgaço-MT. Os extratos foram obtidos por maceração a frio em hexano, diclorometano, acetato de etila, etanol e clorofórmio, rotaevaporado e seco em estufa. No ensaio de difusão em disco, os látex mostraram potente ação contra todas as bactérias, com exceção da $E$. coli, não diferindo quanto à potência e espectro antibacterianos. Extratos em hexano, diclorometano e etanol das folhas mostraram atividade contra $S$. pyogenes, $K$. pneumoniae, $P$. aeruginosa, $S$. typhimurium, $S$. aureus e $S$. epidermidis nas maiores doses. Extratos da entrecasca foram ativos contra $S$. aureus, S. epidermidis, P. aeruginosa, E. faecalis, S. pyogenes, E. coli, $K$. pneumoniae e $S$. typhimurium. Os látex apresentaram espectro de ação e potência maiores que os extratos obtidos da entrecasca e folhas. Dos extratos obtidos da entrecasca, o clorofórmico foi o mais potente, seguido pelo etanólico, indicando a presença de diferentes princípios ativos. $\mathrm{Na}$ microdiluição em caldo, os látex e extratos foram ativos, porém com maior potência para os primeiros. Os resultados evidenciam atividade antibacteriana para C. urucurana, em diferentes partes da planta e por diferentes metabólitos secundários.
\end{abstract}

Unitermos: Croton urucurana, Euphorbiaceae, atividade antibacteriana.

\begin{abstract}
In vitro screening of antibacterial activity of the latex and extracts from Croton urucurana Baillon”. We evaluated the antibacterial activity of the latex and extracts from different polarities and pharmacogens of Croton urucurana using antimicrobial assays. The pharmacogens were collected in Barão de Melgaço-MT. The extracts were obtained by cold maceration in hexane, dichloromethane, ethyl acetate, ethanol and chloroform. They were concentrated in rotatory evaporator and dried in stove. In the disk diffusion assay, the latex showed a potent action against all bacterial strains, excepting $E$. coli, not differing in the potency and antibacterial spectrum. The hexane, dichloromethane and ethanol extracts of leaves showed activity against $S$. pyogenes, $K$. pneumoniae, $P$. aeruginosa, $S$. typhimurium, $S$. aureus and $S$. epidermidis in the major doses. Extracts obtained of stem bark were actives against $S$. aureus, $S$. epidermidis, P. aeruginosa, E. faecalis, S. pyogenes, E. coli, K. pneumoniae and S. typhimurium. The latex showed higher potency and broad-spectrum of action than extracts from stem bark and leaves. Among the stem bark extracts, the chloroform was the most potent one, followed by the ethanol extract. This result suggests the presence of different active principles. In the brothmicrodilution, the latex and all extracts showed activity, even though, the latex presented more potency. Our results indicate that $C$. urucurana presents antibacterial activity, in different parts of the plant and by different secondary metabolites.
\end{abstract}

Keywords: Croton urucurana, Euphorbiaceae, antibacterial activity.

\section{INTRODUÇÃO}

Deparando-se com a problemática da resistência bacteriana aos antibióticos disponíveis no mercado, tornam-se necessárias pesquisas voltadas ao estudo e avaliação de produtos naturais com propriedades antibióticas. Entre as principais ferramentas na busca de novas moléculas, destacam-se os estudos etnofarmacológicos (Rates, 2001; Albuquerque \& Hanazaki, 2006). O Brasil possui a maior diversidade genética vegetal e étnico-cultural, sendo fonte de novos fármacos (Simões et al., 2000). Estima-se que $50 \%$ dos fármacos empregados para o tratamento de infecções sejam de origem natural ou semi-sintética, bem como $19,4 \%$ dos produtos naturais como protótipos para medicamentos sintéticos (Pretto, 2005).

O gênero Croton é um dos maiores da família Euphorbiaceae, com cerca de 800 espécies distribuídas entre as Américas e a Ásia. Estudos realizados com algumas espécies de Croton têm revelado várias atividades farmacológicas e constituintes químicos como terpenóides, flavonóides e alcalóides (Palmeira 
Júnior et al., 2006; Souza et al., 2006; Costa et al., 2007; Perazzo et al., 2007; Torrico et al., 2007; Rocha et al., 2008; Bertucci et al., 2008).

Croton urucurana Baillon é conhecida popularmente como sangra d’água e sangue de dragão (Mattos, 2002). Comumente encontrada no cerrado mato-grossense, é usada na medicina popular para infecções, diarréia, inflamações, câncer e feridas (Gurgel et al., 2001; Gurgel et al., 2005; Peres et al., 1997; Milo et al., 2002). Da entrecasca de C. urucurana foram isolados ácido acetilaleuritólico e catequinas ativos contra $S$. aureus e $S$. typhimurium (Peres et al., 1997). São referidos também os isolamentos de esteróis (sitosterol, estigmasterol e campesterol), diterpenos (sonderianina), compostos fenólicos da entrecascas, estes com propriedades analgésicas, sendo a sonderianina também dotada de atividade específica para Mycobacterium smigmatis e $S$. aureus (Peres et al., 1997; Peres et al., 1998a,b; Craveiro et al., 1982).

O presente estudo teve por objetivo avaliar a atividade antibacteriana dos látex seco e in natura e de extratos de diferentes polaridades e farmacógenos de Croton urucurana contra bactérias gram-positivas e gram-negativas, usando testes antimicrobianos in vitro.

\section{MATERIAL E MÉTODOS}

\section{Material botânico}

O material botânico (folhas, entrecasca e látex) foi coletado em novembro de 2005, no município de Barão de Melgaço - MT, nas proximidades do Córrego
Areia (elevação $187,15^{\circ} 47^{\prime} 866^{\prime \prime S}$ e 55\%36'356”W). A planta foi identificada pelo botânico Ms. Harry Lorenzi do Instituto Plantarum para Estudos da Flora, Nova Odessa-SP e, uma amostra do material florífero foi depositada no Herbário Central da UFMT (excicata $n^{\circ}$ 35011).

\section{Preparo dos extratos}

Do látex coletado, $150 \mathrm{ml}$ foram secos em estufa $\left(40^{\circ} \mathrm{C}\right)$ e $30 \mathrm{ml}$ do látex vermelho in natura armazenados em geladeira. Os extratos das folhas e entrecasca foram obtidos pelo processo de maceração seqüencial a frio em solventes hexano, diclorometano, acetato de etila, etanol $75 \%$ e clorofórmio, este último apenas para a entrecasca, concentrados em rotaevaporador à $45^{\circ} \mathrm{C}$, sendo o solvente residual eliminado em estufa à $45^{\circ} \mathrm{C}$. No momento de uso, os extratos foram dissolvidos em água destilada estéril ou com o auxílio de Tween 80 $\left(\right.$ Synth $\left.^{\circledR}\right)$.

\section{Microorganismos usados no bioensaio}

As cepas bacterianas envolvidas no estudo foram da marca Newprov ${ }^{\circledR}$, ATTC: Enterococcus faecalis 29212, Staphylococcus aureus 25923, Staphylococcus epidermidis 12228, Streptococcus pyogenes 19615, Escherichia coli 25922, Klebsiella pneumoniae 13883, Pseudomonas aeruginosa 27853, Salmonella typhimurium 14028, Shigella flexneri 12022).

\section{Ensaios antibacterianos}

Tabela 1. Triagem da atividade antibacteriana dos látex in natura e seco de Croton urucurana pelo método de difusão em disco.

\begin{tabular}{|c|c|c|c|c|c|c|c|c|c|c|}
\hline \multirow{2}{*}{$\begin{array}{l}\text { Croton } \\
\text { urucurana }\end{array}$} & \multicolumn{10}{|c|}{ Diâmetro dos halos de inibição (mm) } \\
\hline & $\begin{array}{c}\text { Dose } \\
\text { (mg/disco) }\end{array}$ & & & & & actér & & & & \\
\hline \multirow{6}{*}{ Látex in natura } & 1,0 & $E f$ & $S a$ & $\mathrm{Se}$ & $S p$ & $E c$ & $K p$ & $\mathrm{~Pa}$ & St & $S f$ \\
\hline & 1,0 & $12^{\mathrm{a}}$ & 14 & 14 & 14 & $--^{b}$ & 18 & 18 & 12 & 14 \\
\hline & 0,5 & 10 & 12 & 12 & 12 & -- & 14 & 14 & 10 & 12 \\
\hline & 0,25 & -- & 10 & 10 & 10 & -- & 12 & 12 & 8 & 10 \\
\hline & 0,125 & -- & - & - & -- & -- & -- & 8 & -- & -- \\
\hline & 0,0625 & -- & -- & -- & -- & -- & -- & -- & -- & -- \\
\hline \multirow{5}{*}{ Látex seco } & 1,0 & 10 & 12 & 12 & 14 & -- & 18 & 18 & 12 & 12 \\
\hline & 0,5 & -- & 8 & 10 & 12 & -- & 10 & 15 & 10 & 10 \\
\hline & 0,25 & -- & -- & 8 & 10 & -- & 8 & 13 & 8 & -- \\
\hline & 0,125 & -- & -- & -- & -- & -- & -- & 12 & -- & -- \\
\hline & 0,0625 & -- & -- & -- & -- & -- & -- & 10 & -- & -- \\
\hline Cloranfenicol & $\begin{array}{c}30 \\
\mu \mathrm{g} / \mathrm{disco} \\
\end{array}$ & 30 & 30 & 30 & 30 & 28 & 25 & 25 & 33 & 30 \\
\hline
\end{tabular}

Legenda: $E f=$ Enterococcus faecalis; $S a=$ Staphylococcus aureus; Se = Staphylococcus epidermidis; Sp $=$ Streptococcus pyogenes; Ec $=$ Escherichia coli; $\mathrm{Kp}=$ Klebsiella pneumoniae; $\mathrm{Pa}=$ Pseudomonas aeruginosa; $\mathrm{St}=$ Salmonella typhimurium; Sf $=$ Shigella flexneri $; \mathrm{a}=$ zona de inibição do crescimento bacteriano em $\mathrm{mm} ; \mathrm{b}=$ ausência de inibição do crescimento bacteriano. 


\section{Ensaio de difusão em disco}

Para triagem da atividade antibacteriana de ambos os látex, das folhas e da entrecasca de $C$. urucurana, foi realizado o ensaio de difusão em disco em ágar Muller-Hinton $\left(\mathrm{Oxoid}^{\circledR}\right)$, segundo o método de Bauer et al. (1966), frente a um painel de nove bactérias (5 gram-negativas e 4 gram-positivas), todas ATCC. As placas testes foram preparadas com ágar Muller Hinton e inoculadas sobre sua superfície a respectiva suspensão bacteriana, preparada em salina $0,9 \%$ estéril. A concentração da suspensão bacteriana foi ajustada a escala $1 \mathrm{de}$ MacFarland ( $\left.1 \times 10^{7} \mathrm{UFC} / \mathrm{ml}\right)$.

Os látex e os extratos das folhas e entrecasca foram testados em diferentes doses $(0,062 ; 0,125$; 0,$250 ; 0,5$ e $1,0 \mathrm{mg} /$ disco) utilizando-se como droga padrão, o cloranfenicol $\left(\mathrm{Cecon}^{\circledR}, 30 \mu \mathrm{g} / \mathrm{disco}\right)$. Foram usados como controles negativos, água destilada estéril para os extratos aquosos do látex e Tween 80 em água destilada (3-5\%) para os extratos em hexano e diclorometano (folhas e entrecasca) e extrato em clorofórmio (entrecasca). Os discos de papéis estéreis $\left(\right.$ Cecon $\left.^{\circledR}\right)$ foram impregnados com o extrato teste $(20 \mu \mathrm{l})$ nas diferentes doses e depositados sobre a superfície das placas e estas acondicionadas em geladeira por $4 \mathrm{~h}$. Após esse período, as placas foram incubadas à $37^{\circ} \mathrm{C}$ por 24 horas e, logo após, procedeu-se a mensuração das zonas de inibição de crescimento bacteriano, considerando-se ativos os halos de inibição de crescimento bacteriano $\geq$ à $10 \mathrm{~mm}$. A triagem antibacteriana foi realizada em duplicata (Bauer et al., 1966; Barry et al., 1979).

\section{Microdiluição em placas}

A concentração inibitória mínima (CIM) dos extratos aquosos do látex seco e in natura e dos extratos em clorofórmio e etanol $75 \%$ da entrecasca, foi obtida através da metodologia de microdiluição em caldo, contra nove bactérias (5 gram-negativas e 4 grampositivas), todas ATCC. Para determinar os valores do CIM foram usadas microplacas de 96 cavidades. Da solução mãe $(1 \mathrm{mg} / \mathrm{ml})$ dos látex ou de cada extrato foi

Tabela 2. Triagem da atividade antibacteriana dos extratos das folhas de Croton urucurana pelo método de difusão em disco.

\begin{tabular}{|c|c|c|c|c|c|c|c|c|c|c|}
\hline \multirow{3}{*}{$\begin{array}{l}\text { Croton } \\
\text { urucurana }\end{array}$} & \multicolumn{10}{|c|}{ Diâmetro dos halos de inibição (mm) } \\
\hline & \multirow{2}{*}{$\begin{array}{c}\text { Dose } \\
\text { (mg/disco) }\end{array}$} & \multicolumn{9}{|c|}{ Bactérias } \\
\hline & & Ef & $S a$ & $\mathrm{Se}$ & $S p$ & $E c$ & $K p$ & $P a$ & $S t$ & $S f$ \\
\hline \multirow{5}{*}{$\mathrm{EH}$} & 1,0 & $--^{b}$ & -- & -- & $10^{\mathrm{a}}$ & -- & 12 & 13 & 10 & -- \\
\hline & 0,5 & -- & -- & -- & -- & -- & 10 & 10 & -- & -- \\
\hline & 0,25 & -- & -- & -- & -- & -- & 8 & 8 & -- & -- \\
\hline & 0,125 & -- & -- & -- & -- & -- & -- & -- & -- & -- \\
\hline & 0,0625 & -- & -- & -- & -- & -- & -- & -- & -- & -- \\
\hline \multirow{5}{*}{ EDCM } & 1,0 & -- & -- & -- & 12 & -- & -- & -- & -- & -- \\
\hline & 0,5 & -- & -- & -- & 10 & -- & -- & -- & -- & -- \\
\hline & 0,25 & -- & -- & -- & -- & -- & -- & -- & -- & -- \\
\hline & 0,125 & -- & -- & -- & -- & -- & -- & -- & -- & -- \\
\hline & 0,0625 & -- & -- & -- & -- & -- & -- & -- & -- & -- \\
\hline \multirow{5}{*}{ EA } & 1,0 & -- & -- & -- & -- & -- & -- & -- & -- & -- \\
\hline & 0,5 & -- & -- & -- & -- & -- & -- & -- & -- & -- \\
\hline & 0,25 & -- & -- & -- & -- & -- & -- & -- & -- & -- \\
\hline & 0,125 & -- & -- & -- & -- & -- & -- & -- & -- & -- \\
\hline & 0,0625 & -- & -- & -- & -- & -- & -- & -- & -- & -- \\
\hline \multirow{5}{*}{$\mathrm{EE}$} & 1,0 & -- & 10 & 10 & 10 & -- & -- & -- & 12 & -- \\
\hline & 0,5 & -- & 8 & -- & -- & -- & -- & -- & 10 & -- \\
\hline & 0,25 & -- & -- & -- & -- & -- & -- & -- & -- & -- \\
\hline & 0,125 & -- & -- & -- & -- & -- & -- & -- & -- & -- \\
\hline & 0,0625 & -- & -- & -- & -- & -- & -- & -- & -- & -- \\
\hline Cloranfenicol & $\begin{array}{c}30 \\
\mu \mathrm{g} / \mathrm{disco}\end{array}$ & 30 & 30 & 0 & 30 & 28 & 25 & 25 & 33 & 30 \\
\hline
\end{tabular}

Legenda: $\mathrm{EH}=$ extrato em hexano; $\mathrm{EDCM}=$ extrato em diclorometano; $\mathrm{EA}=$ extrato em acetato de etila; $\mathrm{EE}=$ extrato em etanol 75\%; Ef = Enterococcus faecalis; Sa = Staphylococcus aureus; Se = Staphylococcus epidermidis; Sp = Streptococcus pyogenes; $E c=$ Escherichia coli; $K p=$ Klebsiella pneumoniae; $P a=$ Pseudomonas aeruginosa; $S t=$ Salmonella typhimurium; $S f=S h i g e l l a$ flexneri; $\mathrm{a}=$ zona de inibição do crescimento bacteriano em $\mathrm{mm} ; \mathrm{b}=$ ausência de inibição do crescimento bacteriano. 
Tabela 3. Triagem da atividade antibacteriana dos extratos da entrecasca de Croton urucurana pelo método de difusão em disco.

\begin{tabular}{|c|c|c|c|c|c|c|c|c|c|c|}
\hline \multirow{3}{*}{$\begin{array}{l}\text { Croton } \\
\text { urucurana }\end{array}$} & \multicolumn{10}{|c|}{ Diâmetro dos halos de inibição (mm) } \\
\hline & \multirow{2}{*}{$\begin{array}{c}\begin{array}{c}\text { Dose } \\
\text { (mg/disco) }\end{array} \\
1,0\end{array}$} & \multicolumn{9}{|c|}{ Bactérias } \\
\hline & & $E f$ & $S a$ & $\mathrm{Se}$ & $S p$ & $E c$ & $K p$ & $\mathrm{~Pa}$ & $S t$ & Sf \\
\hline \multirow{5}{*}{$\mathrm{EH}$} & 1,0 & $--^{b}$ & $12^{\mathrm{a}}$ & 10 & -- & -- & -- & 17 & -- & -- \\
\hline & 0,5 & -- & 8 & 8 & -- & -- & -- & 14 & -- & -- \\
\hline & 0,25 & -- & -- & -- & -- & -- & -- & 12 & -- & -- \\
\hline & 0,125 & -- & -- & -- & -- & -- & -- & -- & -- & -- \\
\hline & 0,0625 & -- & -- & -- & -- & -- & -- & -- & -- & -- \\
\hline \multirow{5}{*}{ EDCM } & 1,0 & -- & 12 & 10 & -- & -- & -- & 13 & -- & -- \\
\hline & 0,5 & -- & 8 & -- & -- & -- & -- & 10 & -- & -- \\
\hline & 0,25 & -- & -- & -- & -- & -- & -- & 8 & -- & -- \\
\hline & 0,125 & -- & -- & -- & -- & -- & -- & -- & -- & -- \\
\hline & 0,0625 & -- & -- & -- & -- & -- & -- & -- & -- & -- \\
\hline \multirow{5}{*}{$\mathrm{EC}$} & 1,0 & 14 & 14 & 12 & 18 & 12 & 14 & 15 & -- & -- \\
\hline & 0,5 & 12 & 12 & 8 & 15 & 8 & 12 & 12 & -- & -- \\
\hline & 0,25 & -- & 10 & -- & 12 & -- & 10 & 10 & -- & -- \\
\hline & 0,125 & -- & -- & -- & -- & -- & -- & 8 & -- & -- \\
\hline & 0,0625 & -- & -- & -- & -- & -- & -- & -- & -- & -- \\
\hline \multirow{5}{*}{ EA } & 1,0 & -- & 8 & 10 & 8 & -- & 20 & -- & -- & -- \\
\hline & 0,5 & -- & -- & -- & -- & -- & 16 & -- & -- & -- \\
\hline & 0,25 & -- & -- & -- & -- & -- & 12 & -- & -- & -- \\
\hline & 0,125 & -- & -- & -- & -- & -- & -- & -- & -- & -- \\
\hline & 0,0625 & -- & -- & -- & -- & -- & -- & -- & -- & -- \\
\hline \multirow{5}{*}{$\mathrm{EE}$} & 1,0 & 12 & 12 & -- & 18 & 12 & -- & 15 & 10 & -- \\
\hline & 0,5 & 10 & -- & -- & 14 & 8 & -- & 13 & -- & -- \\
\hline & 0,25 & -- & -- & -- & 12 & -- & -- & 10 & -- & -- \\
\hline & 0,125 & -- & -- & -- & -- & -- & -- & -- & -- & -- \\
\hline & 0,0625 & -- & -- & -- & -- & -- & -- & -- & -- & -- \\
\hline Cloranfenicol & $\begin{array}{c}30 \\
\mu \mathrm{g} / \mathrm{disco}\end{array}$ & 30 & 30 & 30 & 30 & 28 & 25 & 25 & 33 & 30 \\
\hline
\end{tabular}

Legenda: $\mathrm{EH}=$ extrato em hexano; $\mathrm{EDCM}=$ extrato em diclorometano; $\mathrm{EC}=$ extrato em clorofórmio; $\mathrm{EA}=$ extrato em acetato de etila; EE = extrato em etanol 75\%; Ef = Enterococcus faecalis; $S a=$ Staphylococcus aureus; $S e=$ Staphylococcus epidermidis; $S p$ $=$ Streptococcus pyogenes; $E c=$ Escherichia coli; Kp =Klebsiella pneumoniae; $P a=$ Pseudomonas aeruginosa $;$ St $=$ Salmonella typhimurium; $S f=$ Shigella flexneri; $\mathrm{a}=$ zona de inibição do crescimento bacteriano $\mathrm{em} \mathrm{mm} ; \mathrm{b}=$ ausência de inibição do crescimento bacteriano.

feita a diluição seriada $(0,0625-0,125-0,25-0,5$ e 1,0 $\mathrm{mg} / \mathrm{ml}$ ) e adicionados $100 \mu \mathrm{l}$ de cada diluição ao meio de Muller-Hinton. Em seguida, as placas foram inoculadas com $100 \mu \mathrm{l}$ de cada bactéria, ajustadas à escala $1 \mathrm{de}$ MacFarland $\left(1 \times 10^{7} \mathrm{UFC} / \mathrm{ml}\right)$, incubadas à $37^{\circ} \mathrm{C}$ por 24 horas e realizada a leitura das microplacas.

A CIM representa a menor concentração da droga teste capaz de inibir completamente o crescimento bacteriano no meio (NCCLS - Document M7-A6, 2003). Os testes foram realizados em duplicata.

\section{RESULTADOS E DISCUSSÃO}

Nas tabelas 1, 2 e 3 podem ser vistos os resultados do ensaio de difusão em disco. O látex seco nas doses de 0,0625 à $1,0 \mathrm{mg} /$ disco e o látex in natura nas doses de 0,125 a $1,0 \mathrm{mg} /$ disco exibiram zona de inibição de 8 à $18 \mathrm{~mm}$, exceto para $E$. coli, para a qual ambos os látex foram inativos. Em relação à potência, verificouse maiores halos de inibição para $K$. pneumoniae e $P$. aeruginosa $(10-18 \mathrm{~mm})$. Esses resultados indicam que os compostos polares presentes nos látex sejam os responsáveis pela atividade antibacteriana (Tabela 1). O extrato em hexano das folhas apresentou maior espectro de ação para as bactérias gram-negativas e potente ação contra K. pneumoniae e $P$. aeruginosa, formando zonas 
Tabela 4. Atividade antibacteriana dos látex in natura e seco e dos extratos em etanol e clorofórmio da entrecasaca de Croton urucurana no ensaio de microdiluição em caldo.

\begin{tabular}{lcccc}
\hline & \multicolumn{3}{c}{ CIM $(\mathrm{mg} / \mathrm{mL})^{\mathrm{a}}$} \\
\cline { 2 - 5 } CEPAS & \multicolumn{2}{c}{ Látex } & Etanol & Cxtratos \\
\cline { 2 - 5 } & in natura & seco & 0,5 & 0,5 \\
E. faecalis & 0,25 & 0,125 & 0,5 & 1,0 \\
S. aureus & 0,25 & 0,25 & 0,25 & 1,0 \\
S. epidermidis & 0,25 & 0,25 & 0,5 & 0,5 \\
S. pyogenes & 0,25 & 0,5 & 0,25 & 0,25 \\
E. coli & 0,25 & 0,125 & 0,5 & 0,25 \\
K. pneumoniae & 0,25 & 0,25 & 0,25 & 0,25 \\
P. aeruginosa & 0,125 & 0,125 & 0,25 & 0,25 \\
S. typhimurium & 0,25 & 0,25 & 0,5 & 0,25 \\
S. flexneri & 0,25 & 0,25 & & \\
\hline
\end{tabular}

${ }^{a} \mathrm{CIM}$ - concentração inibitória mínima.

de inibição de $10-13 \mathrm{~mm}(0,5$ e $1,0 \mathrm{mg} /$ disco $)$, enquanto que o extrato em diclorometano foi ativo apenas para $S$. pyogenes com halos de 10-12 $\mathrm{mm}$ nas mesmas doses. O extrato em etanol $75 \%$ das folhas apresentou maior espectro de ação para bactérias gram-positivas e potente ação contra $S$. typhimurium $(0,5$ e $1,0 \mathrm{mg} /$ disco) com halos de 10-12 mm. O extrato em acetato de etila mostrou-se inativo. Com base nesses achados, sugere-se que os princípios ativos presentes nas folhas tenham baixa polaridade e possivelmente não se tratam de flavonóides (Tabela 2).

Os extratos em hexano e diclorometano da entrecasca mostraram atividade contra as bactérias $S$. aureus, $S$. epidermidis e $P$. aeruginosa $(0,25-1,0 \mathrm{mg} /$ disco), produzindo halos de inibição de 10-17 mm. Apresentam, portanto pequeno espectro de ação, porém com potente ação contra $P$. aeruginosa $(0,5$ e $1,0 \mathrm{mg} /$ dose). O extrato em clorofórmio apresentou amplo espectro de ação, sendo o mais potente dos extratos contra E. faecalis, S. aureus, S. pyognes, K. pneumoniae, não sendo ativo apenas para $S$. flexneri e $S$. typhimurium. $\mathrm{O}$ extrato em acetato de etila da entrecasca apresentou pequeno espectro de ação, sendo ativo apenas para $K$. pneumoniae e $S$. epidermidis (10-20 mm). O extrato em etanol $75 \%$ mostrou amplo espectro de ação e potente ação antibacteriana contra $E$. faecalis, $S$. pyogenes, $P$. aeruginosa (Tabela 3). Tanto os extratos da entrecasca de $C$. urucurana preparados com solventes de baixa polaridade (clorofórmio) quanto de alta polaridade (etanol 75\%) apresentaram atividade antibacteriana significativa. Estes solventes são bons extratores de substâncias ativas como flavonóides, alcalóides e terpenos. Esses resultados estão de acordo com os de Peres et al. (1997), que relatam as presenças de catequina e ácido acetilaleuritólico isolados da entrecasca e ativos para $S$. aureus e $S$. typhimurium. Cloranfenicol (30 $\mu \mathrm{g} /$ disco), droga padrão, exibiu zona de inibição de crescimento entre $25-35 \mathrm{~mm}$.

A atividade antibacteriana pelo método de difusão em disco apresentou variação da zona de inibição formada, entre os extratos apolares e polares das folhas e entrecasca. O tamanho da zona de inibição de crescimento é influenciado pela velocidade de difusão das substâncias no ágar (Virtuoso et al., 2005); tendo os extratos apolares maiores dificuldades de difusão no ágar, o que pode explicar, em parte, a menor atividade verificada para os extratos em hexano e diclorometano comparada com os látex e extratos polares.

O látex seco e in natura apresentaram atividade antibacteriana semelhantes, com espectro de ação e potência maiores que a atividade apresentada pelos extratos obtidos das folhas e entrecasca. O látex seco e in natura e os extratos em clorofórmio e etanol $75 \%$ da entrecasca apresentaram as melhores atividade antibacteriana no ensaio de difusão em disco, e por isso foram selecionados para determinações do CIM's.

Os dois látex e extratos não apresentaram diferenças quanto ao espectro de ação, porém o látex seco mostrou maior potência antibacteriana contra E. coli, $P$. aeruginosa e E. faecalis (CIM $=0,125 \mathrm{mg}$ / $\mathrm{ml}$ ). O extrato em etanol apresentou maior potência para as bactérias gram-positivas, comparada ao extrato em clorofórmio, o qual não apresentou diferença de potência para bactérias gram-negativas e gram-positivas (Tabela 4). Os extratos obtidos do látex seco e in natura e os extratos da entrecasca em clorofórmio e etanol 75\% foram ativos frente a todas as bactérias testadas, mesmo para aquelas que mostraram resistentes no método de difusão em disco. É reconhecido que o método de microdiluição em caldo apresenta maior sensibilidade às drogas do que o método de difusão em disco, pois permite um contato direto entre a droga, o meio de cultura e as bactérias, que são incubadas sob agitação contínua (Hadacek \& Greger, 2000). 
O látex seco e in natura não diferiram quanto à potência e ao espectro de ação antibacteriano nos ensaios realizados, porém apresentaram melhor atividade antibacteriana quando comparada aos extratos obtidos de outros farmacógenos (folhas e entrecasca) (Tabelas 1 e 4$)$.

A abordagem fitoquímica preliminar do látex seco de $C$. urucurana (dados não publicados) revelou as presenças de alcalóides, flavonóides, compostos fenólicos, taninos condensados e esteróides, classes de metabólitos secundários com conhecidos efeitos antimicrobianos (Rauha et al., 2000; Simões et al., 2000; Sartori, 2005; Pretto, 2005).

A presença de atividade antibacteriana no látex seco e in natura e nos extratos obtidos por partição em diferentes solventes e em diferentes partes de $C$. urucurana indica que os princípios ativos são de natureza diferente e distribuem-se de modo não uniforme nas diferentes partes da planta.

\section{AGRADECIMENTOS}

CAPES; FAPEMAT; CNPq; Instituto Plantarum para Estudos da Flora.

\section{REFERÊNCIAS}

Albuquerque UP, Hanazaki N 2006. As pesquisas etnodirigidas na descoberta de novos fármacos de interesse médico e farmacêutico: fragilidades e pespectivas. Rev Bras Farmacogn 16 (Supl.): 678-689.

Barry AL, Thirnsberry C, Gerlach EH, Hawkinson RWDM 1979. Methods of measuring zone of inhibition whit the Bauer-Kirby disk susceptibility test. J Clin Microbiol 6: 885-889.

Bauer AW, Perry MB, Kirby WMM 1966 Antibiotic susceptibility testing by a standardized single disk method. Am J Clin Pathol 45: 493-496.

Bertucci A, Haretche F, Olivaro C, Vázquez A, 2008. Prospección química del bosque de galería del río Uruguay. Rev Bras Farmacogn 18: 21-25.

Costa MP, Magalhães NSS, Gomes FES, Maciel MAM 2007. Uma revisão das atividades biológicas da transdesidrocrotonina, um produto natural obtido de Croton cajucara. Rev Bras Farmacogn 17: 275-286.

Craveiro A, Silveira ER, Braz Filho R, Mascarenhas IP 1982. Sonderianin, a furanoid diterpene from Croton urucurana. Phytochemistry 20: 852-854.

Gurgel LA, Silva RM, Santos FA, Martins DT, Mattos PO, Rao VS 2001. Studies on the antidiarrhoeal effect of dragon's blood from Croton urucurana. Phytother Res 15: 319-322.

Gurgel LA, Sidrim JJ, Martins DT, Filho CV, Rao VS 2005. In vitro antifungal activity of dragon's blood from Croton urucurana against dermatophytes. $J$ Ethnopharmacol 97: 409-412.

Hadecek F, Greger H 2000. Testing of antifungal natural productos: methodologies, comparability of results and assay choice. Phytochem Anal 11: 137-147.

Mattos PEO 2002. Validação pré-clínica das atividades antinociceptivas, antiinflamatória, cicatrizante e avaliação da toxicidade do látex de Croton urucurana Baillon (Sangra D 'Água). Cuiabá, 150p. Dissertação de Mestrado - Programa de Pós-graduação de Saúde Coletiva, Universidade Federal de Mato Grosso.

Milo B, Risco E, Vila R, Iglesias J, Cañigueral S 2002. Characterization of a fucoarabinogalactan, the main polysaccharide from the gum exudate of Croton urucurana. J Nat Prod 65: 1143-1146.

NCCLS 2003. National Committee for Clinical Laboratory Standards. Methods for Diluition Antimicrobial Susceptibility Test for Bacteria That Grow Aerobically: Approved Standard - NCCLS document M7-A6 6th. Wayne.

Palmeira Júnior SF, Alves VL, Moura FS, Vieira LFA, Conserva LM, Lemos RPL Constituintes químicos das folhas e caule de Croton sellowii (Euphorbiaceae). Rev Bras Farmacogn 16: 397-402.

Perazzo FF, Carvalho JCT, Rodrigues M, Morais EKL, Maciel MAM 2007. Comparative anti-infammatory and antinociceptive effects of terpenoids and an aqueous extract obtained from Croton cajucara Benth. Rev Bras Farmacogn 17: 521-528.

Peres MTLP, Monache FD, Cruz AB, Pizzolatti MG, Yunes RA 1997. Chemical and antimicrobial activity of Croton urucurana Baillon (Euphorbiaceae). $J$ Ethnofarmacol 56: 223-226.

Peres MTLP, Pizzolati MG, Yunes RA, Monache FD 1998a. Clerodane diterpenes of Croton urucurana. Phytochemistry 49: 171-174.

Peres MTLP, Monache FD, Pizzolatti MG, Santos ARS, Beirith A, Calixto JB, Yunes RA 1998b. Analgesic compounds of Croton urucurana Baillon. Phamaco chemical criteria used in their isolation. Phytother Res 12: 209-211.

Pretto JB 2005. Potencial antimicrobiano de extratos, frações e compostos puros obtidos de algumas plantas da flora catarinense.Vale do Itajaí, 74p. Dissertação de Mestrado - Programa de Pós-graduação em Ciências Farmacêuticas, Universidade do Vale do Itajaí.

Rates SMK 2001. Plants medicinais de Santa Catarina. Anais Botânicos do Herbário Barbosa Rodrigues 2: 71116.

Rauha JP, Remes S, Heimonen M, Hopia A, Kahkonem M, Kujala T, Pihlaja K, Vuruoela H 2000. Antimicrobial effects of finnish plant extratcts containing flavonoids and phenoli compounds. Int $J$ Food Microbiol 56: 3-12.

Rocha FF, Neves EMN, Costa EA, Matos LG, Müller AH, Guilhon GMSP, Cortes WS, Vanderlinde FA 2008. Evaluation of antinociceptive and antiinflammatory effects of Croton pullei var. glabrior Lanj. (Euphorbiaceae). Rev Bras Farmacogn 18: 344-349.

Sartori MRK 2005. Atividade antimicrobiana de frações de extratos e compostos puros obtidos das flores da Acmela brasiliensis Spreng (Wedelia paludosa) (Astaraceae). Vale do Itajaí, 82p. Dissertação de mestrado - Programa de Pós-graduação em Ciências Farmacêuticas, Universidade do Vale do Itajaí.

Simões CMO, Schenkel EP, Gosmann G, Mello JCP, Mentz LA, Petrovick PR 2000. Farmacognosia: da planta ao medicamento. Santa Catarina: Editora UFSC.

Souza MAA, Souza SR, Veiga Jr VF, Cortez JKPC, Leal 
RS, Dantas TNC, Maciel MAM 2006. Composição química do óleo fixo de Croton cajucara e determinação das suas propriedades fungicidas. Rev Bras Farmacogn 16 (Supl.): 599-610.

Torrico F, Cepeda M, Guerrero G, Melendez F, Blanco Z, Canelón DJ, Diaz B, Compagnone RS, Suárez AI 2007. Hypoglycaemic effect of Croton cuneatus in streptozotocin-induced diabetic rats. Rev Bras Farmacogn 17: 166-169.

Virtuoso S, Davet A, Dias JFG, Cunico MM, Miguel MD, Oliveira AB, Miguel OG 2005. Estudo preliminar da atividade antibacteriana das cascas de Erythrina velutina Willd, Fabaceae (Leguminosae). Rev Bras Farmacogn 15: 137-141. 